\title{
Sir Alasdair Breckenridge
}

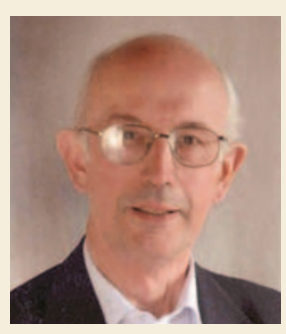

Alasdair Breckenridge, Chairman of the UK Medicines and Healthcare Regulatory Agency (MHRA). Alasdair Breckenridge became involved in the regulation of medicines in the early 1980s. Before he took on his current role, he was Chairman of the UK Committee on Safety of Medicines (which advises Ministers and the MHRA on the regulation of medicines) and Professor of Clinical Pharmacology at the University of Liverpool. Educated at St Andrews University, UK, he then spent 12 years at the Royal Postgraduate Medical School in London before moving to Liverpool University in 1975. He has served on numerous committees and councils involved in the development and regulation of medicines for various diseases, and recently was a member of the Institute of Medicine's committee charged with putting the FDA's drug safety infrastructure under the spotlight. The resulting report, The Future of Drug Safety, was published in September 2006.

\section{How did the Future of Drug Safety report come about?}

After the withdrawal of Vioxx (rofecoxib; Merck) and some other high-profile safety issues, the FDA commissioned the Institute of Medicine (IOM) to examine the way it monitored the safety of medicines after marketing. I was invited to join the committee in April 2005. The first thing we did was to declare conflicts of interest, because that's something that the IOM takes very seriously, and then we read many reports that the FDA provided and we interviewed both the FDA and other stakeholders, including the pharma industry, pharmacists and the public. No one from industry was on the committee, so it was an important part of the process to get a lot of information from these other stakeholders.

\section{What did the report identify as the most important areas for improvement?}

The FDA, just like other regulators, is very good at studying pre-marketing safety and efficacy. Problems often arise after the drug is licensed and on the market. So the committee's most important recommendation was to take a life-cycle approach to risk and benefit - to look at the safety of a medicine from the time it's discovered all the way through its use. This is something people have been talking about for a long time, because it's well known that when you license a medicine it will typically only have been given to around 1,000 patients and so there is little information on safety - the most useful safety data accrue after licensing. The tools available to report on post-marketing safety - yellow cards in the UK and Medwatch in the US - have shortcomings for effective post-marketing surveillance. In addition, many regulators have requested at the time of licensing that companies agree to do further safety studies. But regulators have never had any legal powers to force them to do such studies, and many of the studies that are asked for are never completed. So the committee recommended that the FDA must be given the legal power to ensure that once it asks for a study, that study is done. The next issue is who's going to pay for these large postmarketing studies? The regulators don't have the funds to do it. There are large databases out there that could be used to obtain patient records for analysis - but who's going to pay to use them? More resources are needed for these essential but complicated studies, and for access to IT systems and databases.

\section{Where else might resources come from?} In the US, FDA money essentially comes from two sources: Congress and fees related to the Prescription Drug User Fee Act (PDUFA). At present, $\sim 50-55 \%$ of FDA funds used to regulate medicines come from PDUFA fees, which industry pays to the FDA to put towards resources that allow the agency to review New Drug Applications more quickly. It has worked, as the average time to approval has fallen from about 3 years to less than a year. However, industry insisted that its money was used to accelerate drug approvals, so there has been an imbalance in the amount of resources given to the Office of New Drugs compared with funds available to the Office of Drug Safety. These 'conditions' set by industry have been slackened slightly since the original Act in 1992, but we have put recommendations in our report that propose that these fees are directed specifically for studies on drug safety when PDUFA is renegotiated in 2007.
We have also made the recommendation that there should be more money from Congress. I believe that regulation should follow science so I was pleased that the report proposed that there should be an 'Office of the Chief Scientist' that focuses on the science of regulation from within the FDA, and we believe that this should be funded by Congress. But, of course, obtaining funding from government is always difficult.

\section{Did any lessons from European regulation seem applicable to the FDA?}

Yes, there were two aspects that they were particularly keen to learn about. First, when a drug initially enters the market in the $\mathrm{EU}$ or there is a new formulation, we put a black triangle on all advertising material and all patient information to signify that our information on risk:benefit ratio is less than that of an established drug. Second, in Europe we review the risk:benefit ratio of the drug after 5 years. This doesn't happen in the US, but the committee liked the idea and so that has formed part of our recommendations. After 5 years, you can then bring all the evidence on drug safety together, and see whether the companies have fulfilled their post-marketing commitments. It's not a case of taking the drug off the market, because that wouldn't be to the patients' benefit, but it ensures that safety is being monitored and that the companies know this. Another recommendation we made was that while the black triangle symbol is on a drug - in the EU this is usually for 2 years - then there should be no direct-to-consumer advertising.

\section{What feedback have you had on the report?} It has had a lot of publicity in the US lay press, and the FDA Commissioner has welcomed the report and its highlighting of the agency's lack of resources. Inevitably some of our findings will make the FDA feel uncomfortable, because we talk of the disconnect between the Office of New Drugs and the Office of Drug Safety, but hopefully it will provide the management with some evidence to take steps that they might not have been able to do previously. Indeed, even before this report, the FDA had already begun several initiatives to address the issues we identified.

Interview by Joanna Owens 